\title{
Duration of diastole versus cycle length as correlates of left ventricular ejection time ${ }^{1}$
}

\author{
Daniel Weisdorf ${ }^{2}$ and David H. Spodick \\ From the Cardiology Division, Medical Service, Lemuel Shattuck Hospital and the Department of Medicine, \\ Tufts University School of Medicine
}

Studies were done on 82 normal subjects to evaluate cycle length versus duration of diastole as determinants of left ventricular ejection time. Cycle length and its reciprocal, heart rate, had the highest correlation with left ventricular ejection time. Removal of the self-correlation of left ventricular ejection time within cycle length reduces the correlation so that, of all intervals, duration of diastole had the highest correlation as a determinant of left ventricular ejection time. Cycle length and heart rate remain valuable as spuriously close but not misleading correlates for predicting or correcting left ventricular ejection time.

Time-based measurements of the cardiac cycle have proved to be useful correlates of cardiac performance. One well-studied measure of left ventricular function is the left ventricular ejection time (LVET). The relation of the ejection period to cardiac cycle length and stroke volume has been discussed in numerous studies of the determinants of LVET (Weissler, Peeler, and Roehll, 1961; Spodick and Kumar, 1968; Jones and Foster, 1964).

Stroke volume is directly related to LVET. Cycle length, usually expressed as heart rate, serves as a practical correlate of ejection time (Weissler et al., 1961; Spodick and Kumar, 1968; Jones and Foster, 1964; Xenakis, Quarry, and Spodick, 1975; Spodick and St. Pierre, 1970) owing to its effect on stroke volume (Weissler et al., 1961; Schlant, 1974; Harley, Starmer, and Greenfield, 1969). Differences in cycle length are caused mainly by differences in the duration of diastole, which, within limits, is a determinant of the duration of ventricular filling. Filling is a prime determinant of stroke volume and should be of central importance in determining ejection time. In theory, therefore, LVET should be more closely related to the duration of diastole than to the duration of the

Received 3 July 1975.

'Supported by a grant from the National Aeronautics and Space Administration.

${ }^{2}$ Fourth Year Student, Chicago Medical School. Work done during Cardiology Elective in the Cardiology Division, Lemuel Shattuck Hospital. entire cycle. We examined the duration of diastole in comparison with cycle length as correlates of LVET.

\section{Methods}

Studies were made on 82 subjects ( 43 women and 39 men), ages 39 to 69 . All had a normal history, physical examination, and 12-lead electrocardiogram. Supine resting recordings were made of simultaneous electrocardiogram and right carotid pulse curves. Intervals on the curves were measured independently of each other. Each value used in the analysis represents the mean of 5 measured cycles for each subject. Linear regression equations for left ventricular ejection time were calculated vs. cycle length, heart rate, diastolic interval, and cycle length minus LVET. Statistical differences in slopes were tested by the $t$ test for slopes.

\section{Terms}

Cycle length $(R R): \mathrm{RR}$ interval of preceding cycle in milliseconds.

Heart rate $(H R): 60,000 /$ cycle length in beats/minute. $q$ : Initial deflection of $\mathrm{QRS}$ complex in lead II of the electrocardiogram.

$C A R_{u}$ : Time from $\mathrm{q}$ to the onset of the rapid segment of the carotid upstroke (ms)

$C A R_{I n}$ : Time from $\mathrm{q}$ to the carotid incisura (ms).

Diastolic interval $\left(C A R_{I n} \rightarrow q\right)$ : The time from the preceding carotid incisura to the $\mathrm{q}$ wave (ms). This diastolic interval closely approximates to the duration of diastole (Spodick, and St. Pierre, 1970; Craige, 1974; Tavel, 1972).

LVET was plotted against heart rate (HR), cycle 
TABLE 1 Intervals and heart rates

\begin{tabular}{llllll}
\hline & $L V E T(m s)$ & $R R(m s)$ & $H R$ & $C A R I n \rightarrow q(m s)$ & $R R$ minus LVET (ms) \\
\hline Men & $280 \pm 23.0$ & $837 \pm 124 \cdot 1$ & $72.9 \pm 11 \cdot 1$ & $436 \pm 109.2$ & $556 \pm 111 \cdot 1$ \\
Women & $295 \pm 30.4$ & $833 \pm 161 \cdot 8$ & $74.0 \pm 14.9$ & $411 \pm 134 \cdot 4$ & $539 \pm 138.9$ \\
Total & $288 \pm 27.9$ & $835 \pm 144.5$ & $73.0 \pm 13 \cdot 2$ & $423 \pm 122.9$ & $547 \pm 126.0$ \\
\hline
\end{tabular}

Values recorded are the mean \pm 1 standard deviation.

TABLE 2 Data for regression $L V E T=b X+a$

\begin{tabular}{lrllll}
\hline $\mathrm{X}$ & $r$ & $P(r) \star$ & $a$ & $b$ & $P$ (difference in slope) \\
\hline HR & -0.69 & 0.001 & 395 & -1.45 & 0.02 \\
RR & 0.70 & 0.001 & 174 & +0.14 & - \\
CAR In $\rightarrow$ q & 0.63 & 0.001 & 227 & +0.14 & 0.05 \\
RR minus LVET & 0.58 & 0.001 & 217 & +0.13 & 0.05 \\
\hline
\end{tabular}

$\star P$ values in second column are for significance of the correlation ( $r$ ) of each factor $(X)$ with LVET. $P$ values in the last column are for differences in slope (b) for each factor and LVET compared with the RR-LVET slope.

length (RR), and diastolic interval $\left(\mathrm{CAR}_{\ln } \rightarrow \mathrm{q}\right)$. Since RR includes the LVET, this was subtracted from RR to eliminate its autocorrelating influence, so that LVET was also plotted against RR minus LVET.

\section{Results}

The results are summarized in Tables 1 and 2 .

The regression equations and correlation coefficients relating each variable to LVET were as follows:

Heart rate vs. LVET:

LVET $=-1.45 \mathrm{HR}+395 ; \mathrm{r}=-0.69$.

Cycle length vs. LVET:

LVET $=0 \cdot 14 R R+174 ; r=+0 \cdot 70$

Diastolic interval vs. LVET:

$\mathrm{LVET}=0 \cdot 14\left(\mathrm{CAR}_{\mathrm{In}} \rightarrow \mathrm{q}\right)+227 ; \mathrm{r}=+0.63$.

Cycle length minus LVET) vs. LVET:

LVET $=0.13$ (RR minus LVET) $+217 ; \mathrm{r}=$ +0.58 .

\section{Discussion}

The relation of LVET to heart rate and the level of correlation were similar to results in other series (Weissler et al., 1961; Spodick and Kumar, 1968; Willems and Kesteloot, 1967). The level of correlation of LVET with cycle length $(r=0.70)$ was essentially the same as for heart rate $(r=-0.69)$. Since heart rate is derived from the fundamental measurement (cycle length), it is not surprising that the correlation was equivalent. It should be noted that the general relation of RR to LVET is curvilinear, but over the range of rates in this study it is virtually linear (Willems and Kesteloot, 1967). LVET was expected to correlate best with the duration of diastole, which varies inversely with heart rate and is a major determinant of stroke volume. This was, however, not true. Diastole showed a lower correlation $(r=0.63)$ with LVET than did cycle length. But the RR interval includes LVET and hence LVET is being partly correlated with itself. When LVET is plotted against cycle length excluding ejection time (ie, RR minus LVET) the level of correlation $(r=0.58)$ is indeed lower. That is, LVET is less well correlated with cycle length when the autocorrelation factor is excluded.

These results unmask the autocorrelating factor and the resulting spuriously high correlation of LVET with cycle length (and heart rate), but they do not invalidate the use of RR or heart rate as indices for evaluating ejection time. The LVET vs. $R R$ and LVET vs. $\left(C A R_{I n} \rightarrow q\right)$ regressions have parallel slopes, indicating equal proportionate influence of differences in each variable. Though the diastolic interval is most highly correlated with LVET, cycle length remains valuable as an easily measured practical correlate.

\section{References}

Craige, E. (1974). Apexcardiography. In Noninvasive Cardio$\log y$, p. 1. Ed. by A. M. Weissler. Grune and Stratton, New York.

Harley, A., Starmer, C. F., and Greenfield, J. C. (1969). Pressure-flow studies in man. An evaluation of the duration of the phases of systole. Fournal of Clinical Investigation, 48, 895 .

Jones, W. B., and Foster, G. L. (1964). Determinants of 
duration of left ventricular ejection in normal young men. fournal of Applied Physiology, 19, 279.

Schlant, R. C. (1974). Normal physiology of the cardiovascular system. In The Heart, 3rd ed., p. 79. Ed. by J. W. Hurst. McGraw Hill, New York.

Spodick, D. H., and Kumar, S. (1968). Left ventricular ejection period. American Heart fournal, 76, 70.

Spodick, D. H., and St. Pierre, J. R. (1970). Pulsus alternans: physiologic study by noninvasive techniques. American Heart fournal, 80, 766.

Tavel, M. E. (1972). Clinical Phonocardiography and External Pulse Recording, 2nd ed. Yearbook Medical Publishers, Chicago.

Weissler, A. M., Peeler, R. G., and Roehll, W. H., Jr. (1961). Relationships between left ventricular ejection time, stroke volume and heart rate in normal individuals and patients with cardiovascular disease. American Heart fournal, $62,367$.

Willems, J., and Kesteloot, H. (1967). The left ventricular ejection time. Its relation to heart rate, mechanical systole and some anthropmetric data. Acta Cardiologica, 22, 401. Xenakis, A. P., Quarry, V. M., and Spodick, D. H. (1975). Immediate cardiac reponse to exercise: physiologic investigation by systolic time intervals at graded work loads. American Heart fournal, 89, 178.

Requests for reprints to Dr. David H. Spodick, Lemuel Shattuck Hospital, 170 Morton Street, Boston, Massachusetts, 02130, U.S.A. 